\title{
Epidemiological Profiles of Murders and Murder Victims in Peninsular Malaysia from 2007 to 2011 as Reported by a Newspaper
}

\author{
${ }^{1}$ Mohammad Rahim K, ${ }^{2}$ Nadiah Syariani M.S, ${ }^{3}$ Geshina Ayu M.S \\ ${ }^{1,2,3}$ Forensic Science Programme, School of Health Sciences, Universiti Sains Malaysia, 16150 Kubang Kerian, \\ Kelantan, Malaysia
}

\begin{abstract}
A five year (2007 - 2011) retrospective study on murder and murder victims in Peninsular Malaysia was carried out to build epidemiological profiles of victims and explore several mechanical profiles of murder. The data were based on reported murder incidents in Peninsular Malaysia by one of the local newspaper (News Straits Times). Throughout the five years, males outnumbered females as victims of murder. The age group most affected was 20 to 29 years old (23.3\%) and the highest prevalence was among the Indian ethnic group (22.6\%). The majority of the victims were local people. Most of the incidents involved single persons (92.6\%) as murder victims. Most of the incidents occurred either between $6.00 \mathrm{pm}$ and $12.00 \mathrm{am}(30.2 \%)$ or between 12.01 am and $6.00 \mathrm{am}(18.2 \%)$. The incidents appeared to frequently occur at home (36.6\%), although most of the bodies were recovered in remote areas (43.5\%) such as cemeteries and isolated estates. Sharp objects (31.0\%) and sharp force trauma (30.1\%) were the most preferred murder weapon and cause of deaths. The chest and abdomen (31.1\%) were the most targeted body parts in killing victims, followed by the head (20.3\%). This study also revealed expressive motivation (31.6\%) as the apparent dominating cause of murder compared to instrumental motivation (19.4\%). The emerged profiles were discussed in relation to murder, criminology and victimology contexts.
\end{abstract}

Keywords: Demographic profile, Malaysia, mechanical profile, murder, newspaper

\section{Introduction}

Murder is an inhuman act with the intention of causing harm or taking other people's life (Alvarez and Bachman, 2003). It is perceived as the most serious (Mohanty et al. 2005) and extreme form of violence (Edirinsinghe and Kitulwatte 2009) committed against a person. The phenomenon of murder seems to differ from one country to another due to cultural, geographical, legislation, and historical differences (Milroy and Ranson 1997; Karlsson 1998; Martin et al. 1999; Mohanty et al. 2006).

In Malaysia, the epidemiological study on murder is meager. There are only a few national studies based on autopsy reports (Bhupinder et al. 2010; Kumar et al. 2010). One of the limitations of these studies is that they focused only on certain states (i.e., Kuala Lumpur and Penang) in Malaysia. Malaysia has 13 states in total and focusing on only one or two states are unlikely to represent the overall scenario of murder incidents in Malaysia. As such, criminologists, scholars and the public within and outside of Malaysia may have incomplete or erroneous information regarding the phenomenon of murder in Malaysia.

To fill this acknowledged gap in knowledge, the present retrospective review aimed to provide some descriptive data and an overview of murder in Peninsular Malaysia based on a review of relevant newspaper coverage. In this review, the term murder refers to 'killing a person', and a murder incident is 'an event in which one or more individuals were killed at the same location and time'. The source of this study's data was taken from one of the local newspapers. The present retrospective study is the first newspaper review which focuses on the epidemiological profiles of murder and murder victims in Peninsular Malaysia.

The aim of the present study is to examine the demographic information of victims and mechanical aspects of murder in Peninsular Malaysia. Later, from the reports; epidemiological profiles of murder victims and mechanical aspects emerged. In this paper, the term 'mechanical aspects' is operationalised as a collective term to indicate several aspects of murder committed by perpetrators such as murder settings, apparent motives, cause of deaths, types of weapon used and targeted body parts of the victims which were gathered from the newspaper. The term 'mechanical aspect' was earlier used by Geberth (2006) to address motives, methods, wound structures, crime scene construction, the cause, manner and time of death. According to Geberth (2006), such aspects are important as they provide clues pertaining to the event itself. In brief, this review makes an attempt to document the epidemiology of murder in Peninsular Malaysia for a period of five years (2007 2011). 
It is hoped that the present paper is able to benefit many key personnel, especially those from the criminal justice system; in order to have some understanding on the epidemiology of murder in Peninsular Malaysia. This is imperative as it may suggest the differences of murderous acts and demographic aspects of murder victims which are vital for cross-cultural and national profiling of the phenomenon of murder. In addition, the present paper is also able to provide a pool of information to the nature and extent of murder in Peninsular Malaysia.

\section{Methodology}

The present review is a five-year retrospective research of murder incidents in Peninsular Malaysia based on reported cases by one of the local newspaper: News Strait Times (NST). NST was selected for the purpose of this review as it is one of the leading dailies in Peninsular Malaysia. NST has also cemented a reputation as the commanding voice in delivering ground-breaking and reliable news in Malaysia (The News Straits Times Press 2012). The collection of printed newspapers was assessed at the National Library of Malaysia.

The methodology using newspapers is well evidenced in previous criminological studies on murder related studies (Websdale and Alvarez 1997; Chimbos 1998; Adinkrah 2008; Roma et al. 2012). As an alternative to police reports, this methodology was used as newspapers provided accessible information from various witnesses simultaneously. It was suggested that the use of newspapers as a source of data collection is important in developing nations where severe restrictions are often placed upon the release of official statistics on murder incidents and access to autopsy reports (Adinkrah 2008).

News on murder cases which were published in NST from the period of 1 January 2007 to 31 December 2011 underwent content analysis on two main issues. The first issue was demography of murder victims. The second issue was mechanical aspects of murder such as murder settings, apparent motives, cause of death, types of weapon used, and targeted body parts of the victims. Incomplete information on murder and murder victims were categorized under unknown category while repeated news which provided the same information were excluded.

\section{Results}

Throughout the five years, 994 murder cases with a total number of 1099 murder victims were reported in the NST for Peninsular Malaysia. Information regarding demographics of these murder victims and mechanical aspects of the murder itself were examined. Demographic information of murder victims was than clustered and a synthesis of findings is provided below (Table 1 is referred).

Table 1. Demographic profile of murder victims

\begin{tabular}{lc}
\hline Demographic profile & $\mathrm{n}(\%)$ \\
\hline Gender & $757(68.8)$ \\
Male & $342(31.1)$ \\
Female & \\
Age (years old) & $133(12.1)$ \\
$0-9$ & $69(6.3)$ \\
$10-19$ & $256(23.3)$ \\
$20-29$ & $249(22.7)$ \\
$30-39$ & $140(12.7)$ \\
$40-49$ & $96(8.7)$ \\
$50-59$ & $42(3.8)$ \\
$60-69$ & $44(4.0)$ \\
70 and above & $70(6.4)$ \\
Unknown & \\
Ethnicity & $236(21.5)$ \\
Malay & $228(20.7)$ \\
Chinese & $248(22.6)$ \\
Indian & $7(6.4)$ \\
Others & $154(14.0)$ \\
Foreigners & $226(20.6)$ \\
Unknown & \\
Nationality & $719(65.4)$ \\
Local & $154(14.0)$ \\
Foreigners & $226(20.6)$ \\
Unknown & \\
Number of victims per incident & \\
One & $920(92.6)$ \\
Two & $54(5.4)$ \\
Three & $12(1.2)$ \\
Four and above & $8(0.8)$ \\
&
\end{tabular}




\begin{tabular}{lc} 
Victim's occupation & \\
Semiskilled & $290(26.4)$ \\
Clerical-skilled & $83(7.6)$ \\
Professionals and managers & $100(9.1)$ \\
Non-working group & $164(14.9)$ \\
Unknown & $462(42.0)$ \\
\hline
\end{tabular}

\section{Demographic profile of murder victims}

As per Table 1 above, six demographic variables were examined. These were gender, age, ethnicity, nationality, number of victims per incident, and the victim's occupation. The results of the content analysis for each demographic variable are presented below.

In terms of gender, the gender dispersion of murdered victims is unequal. Based on gender, males in Peninsular Malaysia were two times more likely to be murder victims compared to females. The data suggested a consistent high prevalence of males as murder victims throughout the five year period.

The majority of the victims were in the age range of 20 to 29 years old (23.3\%), followed by the age group of 30 to 39 years old $(22.7 \%)$. Throughout the five years, 133 murder cases from the total number of cases were observed among children from the age group of 0 to 9 years old. The least number of murder victims were from the age group of 60 to 69 years old $(3.8 \%)$.

This review also reported the ethnic distribution of murder victims in Peninsular Malaysia. There was an almost equal distribution among the three main ethnic groups with slightly more Indian victims $(22.6 \%)$ compared to Malays $(21.5 \%)$ and Chinese $(20.7 \%)$. The majority of murder victims were local people $(65.4 \%)$ and the rest were foreigners. The ratio of the foreigners to locals was 1 to 4.67 (foreigner: local).

Information regarding the number of murder victims per incident was also obtained. It was noted that the majority of murders between 2007 and 2011 involved only single victims (92.6\%). Contrary to public perception, incidents involving multiple victims were very rare. Throughout the five year period, $5.4 \%$ of reported murder news involved two victims, $1.2 \%$ involved three victims, and $0.8 \%$ involved four or more victims. Finally, the most affected working class group was individuals from the group of semiskilled workers (26.4\%). The occupation of $42.0 \%$ of the murder victim was not mentioned in the articles.

\section{Mechanical profile of murders}

As mentioned previously, five issues were selected in formulating the mechanical profile of murders. The five issues were: murder settings, apparent motives, cause of death, types of weapon used, and targeted body parts of the victims (Table 2 is referred). Below are presentations of the content analyses.

Table 2. Mechanical profile of murder

\begin{tabular}{lc}
\hline Mechanical profile & $\mathrm{n}(\%)$ \\
\hline Primary place setting & \\
Home & $364(36.6)$ \\
Public areas & $207(20.8)$ \\
Remote areas & $96(9.7)$ \\
Workplace & $55(5.5)$ \\
Others & $65(6.5)$ \\
Unknown & $207(20.8)$ \\
Secondary place setting & \\
River & $42(27.3)$ \\
Dumpster & $25(16.2)$ \\
Remote areas & $67(43.5)$ \\
Others & $20(13.0)$ \\
Time setting & \\
12.01am-6.00am & $181(18.2)$ \\
6.01am-12.00pm & $114(11.5)$ \\
12.01pm - 6.00pm & $105(10.6)$ \\
6.01pm - 12.00am & $300(30.2)$ \\
Unknown & $294(29.6)$ \\
Apparent motives & \\
Expressive & $314(31.6)$ \\
Instrumental & $193(19.4)$ \\
Unknown & $487(50.0)$ \\
Cause of death & \\
Sharp force trauma & $331(30.1)$ \\
Blunt force trauma & $144(13.1)$ \\
Projectile trauma & $117(10.6)$ \\
Asphyxiation & $90(8.2)$ \\
Multiple trauma & $69(6.3)$ \\
Others & $70(6.4)$ \\
Unknown & $278(25.3)$ \\
& \\
&
\end{tabular}




\begin{tabular}{lc}
\hline Types of murder weapon & \\
Sharp objects & $341(31.0)$ \\
Blunt objects & $150(13.6)$ \\
Firearms & $117(10.6)$ \\
Others & $229(20.8)$ \\
Unknown & $262(23.8)$ \\
Targeted body parts & \\
Head & $223(20.3)$ \\
Chest and abdomen & $342(31.1)$ \\
Neck & $137(12.5)$ \\
Multiple organ & $298(27.1)$ \\
Others & $5(4.5)$ \\
\hline
\end{tabular}

Referring to the primary location of murder, homes $(46.0 \%)$ and public areas $(27.0 \%)$ seemed to be the most prevalent physical setting where the murder was performed. This was followed by remote areas $(12.0 \%)$. Murder in the workplace was also observed in $7.0 \%$ of the total murder incidents reported in the NST.

As for the secondary location of murder, remote areas (44.0\%) were the most prevalent. Here, the secondary location of murder refers to the location where the body of the victim was recovered with the assumption victims were killed elsewhere. At that time as reported in the NST, the actual place of the crime scene was either unknown or unidentified, and under investigation.

With regard to time settings of murder, the timing of murder was categorized into four time zones: $12.01 \mathrm{am}$ to $6.00 \mathrm{am}$ (late midnight to early morning), $6.01 \mathrm{am}$ to 12.00 noon (morning), $12.01 \mathrm{pm}$ to $6.00 \mathrm{pm}$ (afternoon), and $6.01 \mathrm{pm}$ to $12.00 \mathrm{am}$ (late evening to midnight). As reported by the NST, the majority of murders took place between $6.00 \mathrm{pm}$ and $12.00 \mathrm{am}(33.3 \%)$. This was followed by between $12.01 \mathrm{am}$ and 6.00 am $(30.2 \%)$.

To some extent, the apparent motives of some murders were stated in the newspapers. Apparent motives included robbery, quarrel, brawls, love affair, and arguments. As a step for systematic classification, motives were classified as instrumental or expressive. In most of the criminological literatures, motives of murder have been characterized as either instrumental or expressive (Block and Block 1992; Decker 1996).

Block and Block (1992) defined expressive murders as a result of expression, emotions, and psychological states. Taking the contrary view, instrumental murders are performed for some benefits such as financial gain, power, and wealth status. From the murder articles, there were more reports of expressive motives $(63.3 \%)$ compared to instrumental motives $(36.7 \%)$. Therefore, it appears that expressive motives were the dominant cause for many murder incidents in Peninsular Malaysia.

Based on the analysis of murder weapon, either sharp objects (31.0\%) or blunt objects (13.6\%) were more likely used compared to other types of weapons. As for cause of death, sharp force trauma $(40.3 \%)$ appeared to be the most prevalent cause of death. This method was followed by blunt force trauma (17.6\%) and projectile trauma (14.3\%).

The chest and abdomen (36.0\%) were the most common body parts of victims to be attacked by perpetrators. This was followed by the victim's head (33\%) (whereby all such targeted victims succumbed to severe injuries to the head). The neck was the targeted body part in $20 \%$ of the total cases, followed by extremities in $10 \%$ of the total cases.

\section{Discussion}

Literatures focusing on forensic and criminological aspects of murder in Malaysia are too few to make reference to. The present retrospective analysis however attempted to focus on the aspects of victims' demography and mechanical pattern of murder in Peninsular Malaysia based on reported cases in a newspaper over a period of five years. Both aspects are discussed thoroughly. Based on the information obtained, epidemiological profiles of murder victims and mechanical aspects were revealed.

In this study, the first issue tackled was the demographic information of victims. Gathering details on demographic information of victims is very important in understanding the pattern of murder in each country. Siegel (2010) suggested that demographic characteristics help to distinguish between victims and non-victims. With regards to gender as a demography, the majority of murder victims in Peninsular Malaysia were males throughout this study's five year period. One of the reasons that could explain the tremendous involvement of male victims in crime is because they generally work outdoors, have wider interactions with more people, and are more exposed to stress, frustration, and violence (Kumar et al. 2010). Other research have shown that males are at higher risk of homicidal deaths as they are more exposed to the external environment which brings them to frequent physical confrontation as opposed to females (Vij et al. 2010).

Concerning the demography of age, most of the murder victims in Peninsular Malaysia were between 20 and 39 years old. This suggest that this age group is more vulnerable compared to other age groups likely due 
to their higher interaction with other people in their daily working and social lives. This particular finding is consistent with the study conducted by Bhupinder et al. (2010) in Penang Island, Malaysia.

On the matter of murder of the elderly, in Peninsular Malaysia, it appears that people belonging to the veteran group of above 60 years old tend to be the victims of instrumental murder instead of expressive murder. A similar scenario is observed in elderly murder in Portugal (Coelho et al. 2010). The veteran groups, especially females; are prone to be the target of instrumental murder as they are weaker in nature as compared to males and people of other age groups. The weakness possessed by this older group makes them an 'easy target' for robbery incidents (Coelho et al. 2010). As reported by the NST, in many instances robbery-cum-murder took place in homes when the elderly victims were alone.

Overall, the years from 2007 to 2011 demonstrated that the ethnicity of murder victims showed an almost equal distribution among the three main ethnic groups: Malays, Chinese, and Indians. However, considering the total population of each ethnic distribution in Peninsular Malaysia, Indians seem to be the most vulnerable to murder. The higher prevalence of Indians being victimised can be explained by several factors which include the involvement in petty crime, gang related activities, and other social deviancy such as alcoholism and substance abuse (Sidhu 2005). Also, it should be noted that the majority of murder victims in this study were local people. Of the total foreign murder victims the majority were from South East Asian countries like Indonesia, Myanmar, and Vietnam.

In Peninsular Malaysia, most victims between 2007 and 2011 were those classified as semiskilled workers such as normal laborers, odd job workers, lorry drivers, and construction workers. They tended to be the victims of quarrels, brawls, and arguments rather than victims of instrumental murder. Meanwhile, for the same five year duration, the higher working class group like professionals and managers were prone to be the victims of instrumental murder due to business rivalry, profits, or robbery. Therefore, this study suggests that the motive of murder (expressive or instrumental murder) is also associated with victims' occupation and nature of work. In most cases, the number of victims per incident is one. Incidents involving multiple victims were very rare. In incidents involving three or more victims during one incident, the assailants were described as being mentally ill or berserk.

In this study, the second issue investigated was mechanical aspects of murder. Murder setting was the first focus under mechanical aspects of murder. The murder setting is an important element as it plays a pivotal role in criminal events especially when urban and rural areas were involved and compared (Gallup-Black 2005; Shai 2010). From newspaper accounts, the place setting of murder was found to be related with the social interaction between the offender and the victim. Other researchers discovered that when a murder took place in a rural area, victims were most commonly intimate and/or family members of the perpetrators, while in urban areas, strangers were more commonly victimised (Gallup-Black 2005; Shai 2010).

Based on the murder settings, the home seems to be the most prevalent setting for murder to take place in Peninsular Malaysia between the years 2007 and 2011. When murder occurs at home, these include both victims and offenders' homes. The majority of murders in homes involved primary relationships such as parents, siblings, and spouses. To some extent, it also involved secondary relationships such as murder perpetrated by babysitters and maids. Murder perpetrated by strangers included robbery-cum-murder and rape-cum-murder.

Public area is the second most common physical setting in murder cases. Public areas in this study consisted of streets, alleys, restaurants, and entertainment outlets. Murders outside the home (for example, public and remote areas) usually involve secondary relationships like acquaintances and no relationships like strangers. The present observation in this study is consistent with that of the study reported by Cao et al. (2008) in Taiwan. Murders in Taiwan involving primary relationships are more likely to happen in homes, whereas murder involving strangers and acquaintances usually take place in public places such as the streets (Cao et al. 2008).

In some cases, the newspaper only reported the place where the victim's body was recovered since the location of the primary crime scene was still under investigation. Incidentally, this denoted remote areas as sites where the majority of victims' bodies were disposed. These remote areas which included cemeteries, isolated farms, and estates (oil palm and rubber plantations) seem to be the preferred place to dispose and conceal the body of victims. Other than dumping bodies at remote areas, bodies were recovered in burnt form, or chopped into several pieces to make the identification of such bodies difficult.

Dumpsters and rivers also seem to be preferred by murderers to dump their victim's body. In many reported cases, bodies of newborns were recovered from dumping grounds like rubbish bins or communal rubbish heaps. In many instances, the newborn body was recovered with an attached umbilical cord. Such incidents depict that dumping babies were attempts to conceal the birth of a newborn. This is classified as murder in Malaysian Laws under Section 302 for murder or Section 307 for attempting murder. Either underage or unwed mothers are often the suspects in these cases.

Regarding time settings of murder, details about the exact time of murder incidents were not published in many cases (Saint-Martin et al. 2006; Wahlsten et al. 2007; Edirinsinghe and Kitulwatte 2009; Kumar et al. 2010; Shai 2010). From the available data in the NST between 2007 and 2011, it was found that the majority of 
Malaysian murders took place during late evening or night time. This finding is consistent with the time settings of murder in India, where it was identified that the majority of murder occur during late evenings and at night (Mohanty et al. 2005). However, the present observation is in contrast with Sri Lanka, where the majority of murder took place during the daytime (Edirinsinghe and Kitulwatte 2009).

The next focus under mechanical aspects of murder was on the apparent motives for murder. Motive is as an essential component when analysing reasons underlying murder (Collins and Presnell 2006), especially from the perpetrator's viewpoint. Decker (1996) had addressed murder motives as ends of a dichotomy which have been conceptualized as either instrumental or expressive.

In this study, it was found that expressive motivation was the most reported dominating cause of murder. Victims, as reported in the NST; were found to be killed following heated arguments, brawls and quarrels while drunk, over girls, and misunderstandings. While some victims were attacked during the quarrels, others were assaulted a few hours after the brawls with more companions of the assailants joining in.

The former reflected impulsive acts by the perpetrators due to high level of emotional arousal. The later reflected planned action by the perpetrator to intentionally cause harm. Such incidents typically involve purposely selecting weapons. Zilman (1979) proposed that when one is at an extreme level of emotional upset, their cognitive or thinking process is impaired, resulting in hostile or aggressive behavior.

This behavior is described as impulsive as it is learnt so well in the past and becomes 'scripted' in the assailant's mind that they appear instantly and without thought. Therefore, the choices of weapon are mostly objects or instruments that are within reach and available at the scene of the crime itself. Although expressive motives were mostly reported as the apparent dominating cause of murder, some of the murders were instrumentally grounded.

The results also revealed that sharp force trauma was the common cause of death in the five consecutive years studied. This was followed by death due to blunt force trauma. These findings are similar to previous national studies by Bhupinder et al. (2010) and Kumar et al. (2010). These findings are also parallel with the findings of other studies in India (Ghangale et al. 2003; Vij et al. 2010) and Hong Kong (Au and Beh 2011).

The present study found that despite strict firearm possession in Malaysia, firearm deaths were mostly seen in robbery-cum-murder cases. In these incidents, handguns were the most prevalent type of firearm used. The employment of firearms in robbery cases appeared to give the carrier coercive power and increase the tendency to attack without endangering themselves (Wells and Horney 2002). This power enables the carrier to threaten victims using firearms to facilitate compliance of the victims (Tedeschi and Felson 1994). In other cases where victims were shot to death, these reflected the ulterior motive where death was intended since firearms have a tendency to cause death 40 times more than other weapons (Felson and Messner 1996).

From the available newspaper information, multiple methods of killing were observed as a result of more than two combinations of mechanisms. The use of multiple method of killing is likely the result of 'premeditation' instead of 'passion or spontaneous' murder. For example, premeditated murderers tend to use multiple methods such as a combination of slashing and strangulation or stabbing and physical force to make sure that their victim is dead.

It emerged from the content analysis that single wound deaths were more common than multiple wound deaths among murder victims in Peninsular Malaysia for the years between 2007 and 2011. The act of inflicting multiple injuries on victims reflected the criminal intent of the assailants (Vij et al. 2010) such as intentional killing, expression of anger towards victims, or when the crime appeared not to have any witness (Au and Beh 2011).

In Peninsular Malaysia, for the years between 2007 and 2011; multiple killing methods was however commonly evident. This is particularly so in cases of child and spouse abuse-cum-murder. Multiple killing methods include the act of kicking, beating, stomping, strangling, intense shaking and starving. The NST revealed prolonged or continuous abuse that led to death. In other cases where multiple methods were employed, more than one assailant was involved.

The next focus of this study was on the types of weapon used. Sharp cutting weapons such as long knives and Rambo knives featured prominently as the instrument of murder. Other sharp objects like sickles and scissors were also identified as the weapon of choice. In countries with more restrictive gun ownership, such as Malaysia, India, New Zealand and Finland, knives were more prominently used compared to firearms as the tool of violence (Lo et al. 1992; Kivivouri 2007; Kershaw et al. 2008; Vij et al. 2010).

When the act of killing was intended, the choice of weapon was premeditated, such as long knives and knives, aiming mostly at the chest and thoracic region. Such choice of weapon is believed to cause severe injury (Brennan et al. 2006). In respect to this, thorax, neck, head, trunk and limbs are the most common site for injuries for intentional killing or due to an expression of anger (Gill and Catanese 2002; Mohanty et al. 2005; Ambade and Godbole 2006). 
When the murderous act is spontaneous and impulsive, the content analysis revealed the use of both blunt and sharp weapons and objects. The used blunt objects as reported by the NST included wood, metal rods, pipes, steering locks, mortar, and helmets. Objects like scarf, ropes, wire, and towel were commonly identified when strangulation was the murder method.

This may be due to the widespread availability of such materials. Results of studies elsewhere suggest that instrument preferences were influenced by its usage in different cultures and societies (Vougiouklakis and Tsiligianni 2006). For instance, Malaysia has established strict legislation of firearm ownership for citizens, restricting permission only to Government forces such as the Police and Army. Wood, metal rods and pipes are readily available likely due to various simultaneous building and transportation construction in urban and rural areas.

From the reported news, postmortem burning was commonly observed, albeit not as the main cause of death; between the years 2007 and 2011. Victims were burnt by their assailants after being killed for the purpose of crime concealment and to prevent recognition of the corpse. The burnt corpses were often discovered in remote areas like abandoned places (bankrupt factories, derelict buildings, abandoned housing projects) or in outdoor places that see few human traffic, such as cemeteries, isolated farms, edge of jungles and oil palm plantations.

The present study findings are in accordance with a study conducted in Turkey (Tumer et al. 2012). In medico-legal autopsies conducted on burnt corpses to determine the manner of death, researchers found that most burnt corpses found in remote areas demonstrate a strong indication of murder (Tumer et al. 2012) given by the places bodies were retrieved (Fanton et al. 2006).

Finally in this study, the targeted body parts of the victims were examined. When either blunt or sharp weapons were used, the chest and abdomen were more commonly targeted. This was followed by injuries to the head, neck, and extremities. In some instances, other body parts such as private parts like male external genitalia was also targeted by the perpetrators in killing victims; most likely in suspected or confirmed sexual affair scenarios.

Researchers have hypothesised that one's motivation for killing and homicide can be reflected through the numbers of injuries found on victims' bodies (Ong 1999; Au and Beh 2011). In addition, the site of injury is somehow related to the closeness of the relationship between the assailants and victims ( $\mathrm{Au}$ and Beh 2011). For example, researchers discovered that when the victims have a personal relationship with the perpetrators, the presence of injuries was more readily observed in the head, face or neck; especially in intimate partner murder cases. The site of injuries from sharp force trauma has further suggested itself as an indicator to distinguish if the victim is a stranger to the offender (Au and Beh 2011).

Given the characteristics of a typical depressive disorder, death due to the feeling of "sadness" is also seen as a solution to suffering and as an escape route from the world full of pain and sadness (Catanesi et al. 2011). Psychotic offenders were found to use sharp weapons more frequently since these instruments were immediate and available at the particular moment of killing with most injuries inflicted onto the face of the victims (Hakkanen and Laajasalo 2006). Wounding of the abdomen is among the most agonising and slow death that can be inflicted compared to wounding of other body areas. This would suggest either a sadistic assailant or a shorter assailant. Meanwhile, death-dealing injuries to the genitalia reflect lust murder, sexual sadism, or paraphilia (Geberth 1996).

\section{Limitations}

The result of this study should be interpreted with acknowledged limitations. Readers should be noted that not all murders that occurred in Peninsular Malaysia were included in this study. Only murders that reported by NST within time period of 2007 until 2011 were included. Therefore, the actual number of murder, murder victims, and the frequency of mechanical aspects of murder is estimated to be higher and differ from the present results.

Furthermore, lack of some information in the news was another limitation of the present study. In several articles, details about basic demographic information of victims and mechanical aspects of murder were not reported and remain unknown. This was particularly in cases involving mutilated, burnt, decomposed, or severely injured victims.

Another limitation was regarding apparent motives. Such details were not extensively reported in the news since the reported murder was still undergoing investigation. Thus, complete profiles of victims as well as patterns of mechanical aspects could not be revealed for all the murder cases in Peninsular Malaysia for the years between 2007 and 2011. Despite these limitations, the present archival analysis successfully revealed the epidemiological profiles of murder victims and mechanical aspects of murder in Peninsular Malaysia. 


\section{Conclusion}

To conclude, this study provided a synthesis of information regarding the demographic profiles of murder victims and five issues pertaining to the mechanical profile of murders in Malaysia from 2007 and 2011. This study involved content analysis on the murder related news from the NST using the retrospective research method. Some information pertinent to current murder cases emerged and discussed.

In brief, murder in Peninsular Malaysia frequently took place in homes especially at night. In many cases, the bodies of victims were recovered at remote areas and such areas were likely secondary locations. Throughout the studied five year period, males were the dominant gender as murder victims. The most affected age groups were people between 20 to 39 years old.

The majority of cases involved single victims, and sharp force trauma was the common cause of death via the use of sharp weapons and objects. Most of the assaults were targeted at the chest and abdomen. In most cases, expressive motivation was the apparent motivation of murder in Peninsular Malaysia. As such this data analysis offers a better understanding on the epidemiology of murder in Malaysia.

\section{Acknowledgements}

The authors would like to express their sincerest gratitude to USM for the Vice Chancellor Award Programme in supporting this study. The authors would also like to thank Dr. Affizal Ahmad and Ms. Viwashine Narayanan for their support and technical assistance in this research.

\section{References}

[1]. M, Adinkrah, Spousal homicide in contemporary Ghana, Journal of Criminal Justice, 36, 2008, $209-216$

[2]. V.N. Ambade, and H.V. Godbole, Comparison of Wound Patterns in Homicide by Sharp and Blunt Force, Forensic Science International, 156, 2006, 166-170.

[3]. K.I, Au, and S.L. Beh, S.L. Injury patterns of sharp instrument homicides in Hong Kong, Forensic Science International, 204, 2010, 201-204.

[4]. S. Bhupinder, T.K, Kumara, and A.M. Syed, A.M. Pattern of homicidal deaths autopsied at Penang Hospital, Malaysia, 2007-2009, Malaysian Journal of Pathology, 163 (2), 2010, 81-86.

[5]. R. Block, and C. Block, C. Homicide Syndromes and Vulnerability: Violence in Chicago's Community Areas over 25 years, Studies on Crime and Crime Prevention, 1992, 61-87.

[6]. I.R. Brennan, S.C. Moore, and J.P. Shepherd. Non-firearm weapon use and injury severity: priorities for prevention, Injury Prevention, 12, 2006, 395-399.

[7]. L. Cao, C. Hou, and B. Huang. Correlates of the victim-offender relationship in homicide, International Journal of Offender Therapy and Comparative Criminology, 52 (6), 2008, 658-672.

[8]. R. Catanesi, F. Carabellese, G. Troccoli, C. Candelli, I. Grattagliano, B. Solarino et al. Psychopathology and Weapon Choice: A Study of 103 Perpetrators of Homicide or Attempted Homicide, Forensic Science International, 209, 2011, $149-153$.

[9]. P.D. Chimbos. Spousal homicides in contemporary Greece, International Journal of Comparative Sociology, 39, $1998,213-224$.

[10]. L. Coelho, T. Ribeiro, R. Dias, A. Santos and T. Magalhaes. Elder Homicide in the north of Portugal, Journal of Forensic and Legal Medicine, 17, 2010, 383-387.

[11]. K.A. Collins and S.E. Presnell. Elder homicide: a 20-year study, Am. J. Forensic Medical Pathology, 27 (2), $2006,183-187$.

[12]. S.H. Decker. Deviant homicide: A new look at the role of motives and victim-offender relationships, Homicide Studies, 33, 1996, 427-449.

[13]. P.A.S. Edirisinghe and I.D.G. Kitulwatte. Extreme violence - homicide; an analysis of 265 cases from the offices of JMO Colombo and Ragama - a study from Sri Lanka, Legal Medicine, 11 (Suppl. 1), 2009, 363-365.

[14]. L. Fanton, K. Jdeed, S. Tilhet-Coartet and D. Malicier, D. Criminal burning, Forensic Science International, 158, $2006,87-93$.

[15]. R.B. Felson and S.F. Messner. To kill or not to kill? Lethal outcome in injurious attacks, Criminology, 34, 1996, 519-545.

[16]. A. Gallup-Black. Twenty years of rural and urban trends in family and intimate partner homicide, Homicide Studies, 9, 2005, 149173 .

[17]. V.J. Geberth. Practical Homicide Investigation: Tactics, Procedures, and Techniques (4 ${ }^{\text {th }}$ Edition). CRC Press, 1996.

[18]. A.L. Ghangale, S.G. Dhawane, and A.A. Mukherjee. Study of homicidal deaths at Indira Gandhi Medical College, Nagpur, Journal of Forensic Medicine and Toxicology, 20, 2003, 47-51.

[19]. J.R. Gill and C. Catanese. Sharp Injury Fatalities in New York City, Journal Forensic Science, 47, $2002,554-557$.

[20]. H. Hakkanen and T. Laajasalo. Homicide Crime Scene Behaviors in a Finnish Sample of Mentally Ill Offender, Homicide Studies, $10(1), 2006,33-54$

[21]. T. Karlsson. Sharp force homicides in the Stockholm area, 1983-1992, Forensic Science International, 94, 1998, 129-39.

[22]. C. Kershaw, S. Nicholas, and A. Walker. Crime in England and Wales 2007/08: findings from the British Crime Survey, London: Home Office, 2008

[23]. J. Kivivouri. Homicide-Suicide in Finland, 2002-2006. European Society of Criminology, Bologna, 2007.

[24]. V. Kumar, A.K, Li, A.Z. Zainal, D.A, Lee and S.A. Salleh. A study of homicidal death in medicolegal autopsies at UMMC, Kuala Lumpur, Journal of Clinical Forensic Medicine, 12, 2010, 254-257.

[25]. M. Lo, C.V. Jane and T.D Koelmeyer. Homicide in Auckland, New Zealand, A14 Year Study, Am J Forensic Med Pathol, 13, $1992,44-49$

[26]. C.C. Martin, J.A. Melki, and M.A. Guimaraes. Assessment of methods of homicides in a Brazilian city: a preliminary study, Forensic Science International, 106, 1999, 19-25.

[27]. C.M. Milroy and D.L. Ranson, D.L. Homicide trends in the state of Victoria, Australia, Am J Forensic Med Pathology, 18, 1997, 285-289.

[28]. M.K. Mohanty, T.S.M. Kumar, and V. Palimar. Victims of Homicidal Deaths: An Analysis of Variables, Journal of Clinical Medicine, 12, 2005, 302-304. 
[29]. M.K. Mohanty, M.K. Panigrahi, S. Mohanty, and S.K. Das. Victimiologic study of female homicide, Legal medicine, 6, 2006, 151156.

[30]. B.B. Ong. The Pattern of Homicidal Slash/Chop Injuries: A 10 Year Retrospective Study in University Hospital Kuala Lumpur, Journal Clinical Forensic Medicine, 6 (1), 1999, 24-29.

[31]. P. Roma, A. Spacca, M. Pampili, D. Lester, R. Tatarelli, P. Girardi et al. The epidemiology of homicide-suicide in Italy: A newspaper study from 1985 to 2008, Forensic Science International, 214, 2012, 1-5.

[32]. P. Saint-Martin, M. Bouyssy, S. Bathellier, S. Sarraj, and P. O’Byrne. Homicide in tours (Indre-et-Loire, France): a four-year review, Journal of Clinical Forensic Medicine, 13, 2006, 331-334.

[33]. D. Shai. Homicide in the High North: Alaska, 1999-2006, Homicide Studies, 14, 2010, 132-133.

[34]. A.S. Sidhu. The rise of crime in Malaysia, an academic and statistical analysis, Journal of the Kuala Lumpur Royal Malaysia Police College, 4, 2005, 1-28.

[35]. L.J. Siegel. Criminology: Theories, Patterns, and Typologies, 10th ed. Belmont: Wadswoth, 2010.

[36]. J.T. Tedeschi and R.B. Felson. Violence, aggression and coercive actions, Washington D.C.: American Psychological Association, 1994.

[37]. The News Straits Times Press (Malaysia) Berhad. (2012). Available from: www.nstp.com.my

[38]. A.R. Tumer, R. Akcan, E. Karacaoglu, A. Balseven-Odabasi, A. Keten, C. Kanburoglu et al. Postmortem burning of the corpses following homicide, Journal of Forensic and Legal Medicine, 2010, 1-6.

[39]. A. Vij, A. Menon, G. Ritesh, T. Kanchan and P. Rastogi. A Retrospective Review of Homicides in Mangalore, South India, Journal of Forensic and Legal Medicine, 17, 2010, 312-315.

[40]. T. Vougiouklakis and C. Tsiligianni. Forensic and Criminologic Aspects of Murder in North-West (Epirus), Greece, Journal of Clinical Forensic Medicine, 13, 2006, 316-320.

[41]. P. Wahlsten, V. Koiranen, and P. Saukko. Survey of medico-legal investigation of homicides in the city of Turku, Finland, Journal of Clinical Forensic Medicine, 14, 2007, 243-252.

[42]. N. Websdale and A. Alvarez. Forensic journalism as patriarchal ideology: The newspaper construction of homicide-suicide. In F. Y. Bailey \& D. C. Hale (Eds.), Popular culture, crime and justice (pp. 123-141). Belmont, CA: Wadsworth, 1997.

[43]. W. Wells and J. Horney. Weapon effects and individual intent to do harm: influences on the escalation of violence, Criminology, 40, 2002, 265-296

[44]. D. Zillman. Hostility and aggression. Hillsdale, NJ: Lawrence Erlbaum, 1979. 